\title{
Examination of the factorial model of a scale developed to assess body satisfaction in the Brazilian context: a study with people 18 to 40 years old
}

\author{
Wanderson Roberto da Silva ${ }^{1}$ (D) João Marôco ${ }^{2}$ (D) Juliana Alvares Duarte Bonini Campos ${ }^{1}$ (D)
}

Received: 16 August 2020 / Accepted: 19 December 2020

(c) The Author(s), under exclusive licence to Springer Nature Switzerland AG part of Springer Nature 2021

\begin{abstract}
Purpose Confirmatory factor analysis was employed to investigate an instrument developed to assess body satisfaction of Brazilian women and men and to identify participants' body satisfaction level.

Methods Brazilian young adults completed the Body Satisfaction Situational Scale and a sociodemographic questionnaire. A total of 1481 individuals (female $=1035$; male $=446$ ) aged between 18 and 40 years old participated in the study. Factorial, convergent and discriminant validity and reliability were evaluated. An invariance test was performed across sexes using multi-group analysis. The prevalence of body satisfaction among participants was calculated using the final models of the instrument.

Results The complete model of the scale ( 23 items and four factors) was invariant across sexes, but it did not fit the samples even after refinement. Therefore, a theoretical investigation of the scale content was performed based on literature. Thus, a reduced model composed of two factors and ten items was found for each sex. These models showed good validity and reliability to independent samples. About prevalence, most of the women were not at all satisfied with body fat and most of the men were slightly satisfied with body musculature. Further, women and men were moderately satisfied with their face, hair, and skin.

Conclusion A reduced model of the instrument for women and another for men showed adequate indices of construct validity and reliability to samples. The most participants were not very satisfied with their bodies. The results can be useful to develop protocols aiming to promote body satisfaction.

Level of evidence Level V, descriptive cross-sectional study.
\end{abstract}

Keywords Body satisfaction $\cdot$ Body dissatisfaction $\cdot$ Scale $\cdot$ Validity $\cdot$ Reliability

\section{Introduction}

Historically, researchers and clinicians have sought to investigate a variety of unusual forms of body perception and experience reported by individuals [1]. Thus, the study of body image has been extended, and currently, a large set of information is known about this subject. Grogan [2] stated

Wanderson Roberto da Silva

wandersonroberto22@gmail.com

1 Department of Biological Sciences, São Paulo State University (UNESP), Rodovia Araraquara-Jaú, km 01, Araraquara, SP 14800-903, Brazil

2 William James Center for Research (WJCR), ISPA - Instituto Universitário, Lisbon, Portugal that body satisfaction is the key to understanding the development of work on positive body image. Body satisfaction is the degree of appreciation that individuals have with their body or specific parts of their body (e.g., arms, legs, and abdomen). A lower body satisfaction may lead to poorer self-care in terms of health behaviors, such as vomiting, fasting as well as the use of laxatives and diet pills for weight control [3]. Therefore, a relationship exists between poor body satisfaction and increased risk of disordered eating patterns [4]. Furthermore, Cash and Smolak [1] and Grogan [2] highlight that poor body satisfaction represents probably the major factor for increasing levels of low self-esteem, anxiety, and depression.

Negative thoughts and feelings about one's own body can be defined as characteristic of body dissatisfaction $[2,5,6]$ in the attitudinal approach presented by Cash and Smolak 
[1]. Many aspects are investigated to assess body dissatisfaction, such as size, shape, muscle tone, and weight $[3,7,8]$. On the other hand, this concept also can refer to an individual's contemptuous opinions of his/her body (i.e., perceptual approach) and has been the target of several studies aiming to identify a perceived discrepancy between actual body and ideal body [9].

Prevalence of body dissatisfaction is high in different countries, affecting more than $50 \%$ of the adult population $[5,9,10]$. This negative evaluation of the body can be an important predictor for the development of mental disorders, such as binge eating, body dysmorphia, and social anxiety disorder $[5,11]$. Therefore, body dissatisfaction is linked with numerous negative consequences in both women and men, and this can be recognized as a public health problem [10].

Both body satisfaction and dissatisfaction are investigated in men and women of all ages. Body satisfaction is consistently higher in men than women [4]. On the other hand, throughout the 1990s, body dissatisfaction increased in both sexes, particularly pertaining to leanness, fat, and muscularity $[1,7,12]$. The literature $[4,5,10]$ shows that women have higher levels of body dissatisfaction than men; however, both have some level of body concern. Most women want to lose weight and have a slim "hourglass" shape, whereas men want to be heavier (i.e., more muscular) and have an inverted triangle shape $[2,3]$. To achieve these shapes, women and men change behaviors (e.g., eating and level of exercise). Thus, assessing an individual's body satisfaction/dissatisfaction is relevant to identify problems and provide treatments to avoid compromising physical and mental health.

In the last few decades, scientists have extensively invested in the development of measures to evaluate body satisfaction/dissatisfaction [7, 13]. These tools encompass aspects, such as weight, shape, muscle, fat, and size [7]. The literature contains instruments to assess body satisfaction/dissatisfaction, such as Body Parts Satisfaction Scale for Men-BPSS-M [12], Body Satisfaction Scale-BSS [14], Body Image States Scale-BISS [15], and Body Satisfaction Situational Scale-ESSC [16]. BPSS-M and BSS were developed for male and female public, respectively, and this limits their use in other samples. The BISS encompass only items to assess satisfaction with the body as a whole. On the other hand, ESSC investigates satisfaction considering the body as a whole and particular parts of women and men.

Hirata and Pilati [16] proposed the ESSC in the Portuguese language for the Brazilian context. Scale items were constructed by psychometric and psychology experts that adapted eighteen items from body image scales developed for women (e.g., Eating Disorder Inventory) and men (e.g., Male Body Attitudes Scale), and they added five items considering positive and negative feelings of people about attractiveness, shape, size, muscle tone, and fat. The experts also separated the items into four factors (see Fig. 1, original model) and this structure was supported by exploratory factor analysis. With this structure, the authors performed a preliminary validation of ESSC using a Brazilian university sample, but no psychometric study was carried out a posteriori to verify the adequacy of the four-factor model in other contexts.

Thus, the ESSC is available for use in research or clinical protocols to assist in the investigation of body satisfaction/ dissatisfaction in Brazilians who, according to the literature, are a group that strongly value body image $[3,9,17]$. However, we do not know if the results produced by this instrument are valid and reliable since its factorial model has never been evaluated.

In this context, estimating the psychometric properties of psychological measures (i.e., questionnaires and scales) is essential to guarantee the quality of the gathered data [18]. This assessment should be performed using robust statistical methods (e.g., confirmatory factor analysis) that are recommended to support the use of the instrument in different samples and thus produce valid and reliable data [19].

Our first objective was to estimate the psychometric properties of the original ESSC model (i.e., with four factors) for a Brazilian sample composed of the men and women in the community. Considering the differences between the sexes when assessing the body image construct, the objective of this study was to perform the psychometric assessment of the instrument separately for women and men. As a secondary aim, we determined the prevalence of body satisfaction among the participants using the fitted model of the scale.

\section{Methods}

\section{Study design and sample size}

This is an observational cross-sectional study. We calculated the minimum sample size using Monte Carlo simulation [20] and adopted the following criteria: (a) bias of parameters estimates smaller than $10 \%$; (b) coverage of $95 \%$ confidence intervals larger than $91 \%$; and (c) percentage of significant coefficients (power) larger or equal to $80 \%$ [21]. A total of 1000 replications employing sample sizes of 100, 150, 200, 250 , and 300 were simulated. A minimum sample size of 200 was shown to be enough to attain good parameters. Therefore, this estimate was adopted for each sex, since the analyses were performed separately for women and men.

\section{Participants}

Brazilians of both sexes were invited to participate in the study. The inclusion criteria were literate subjects between 18 and 40 years old. The exclusion criteria were as follows: 


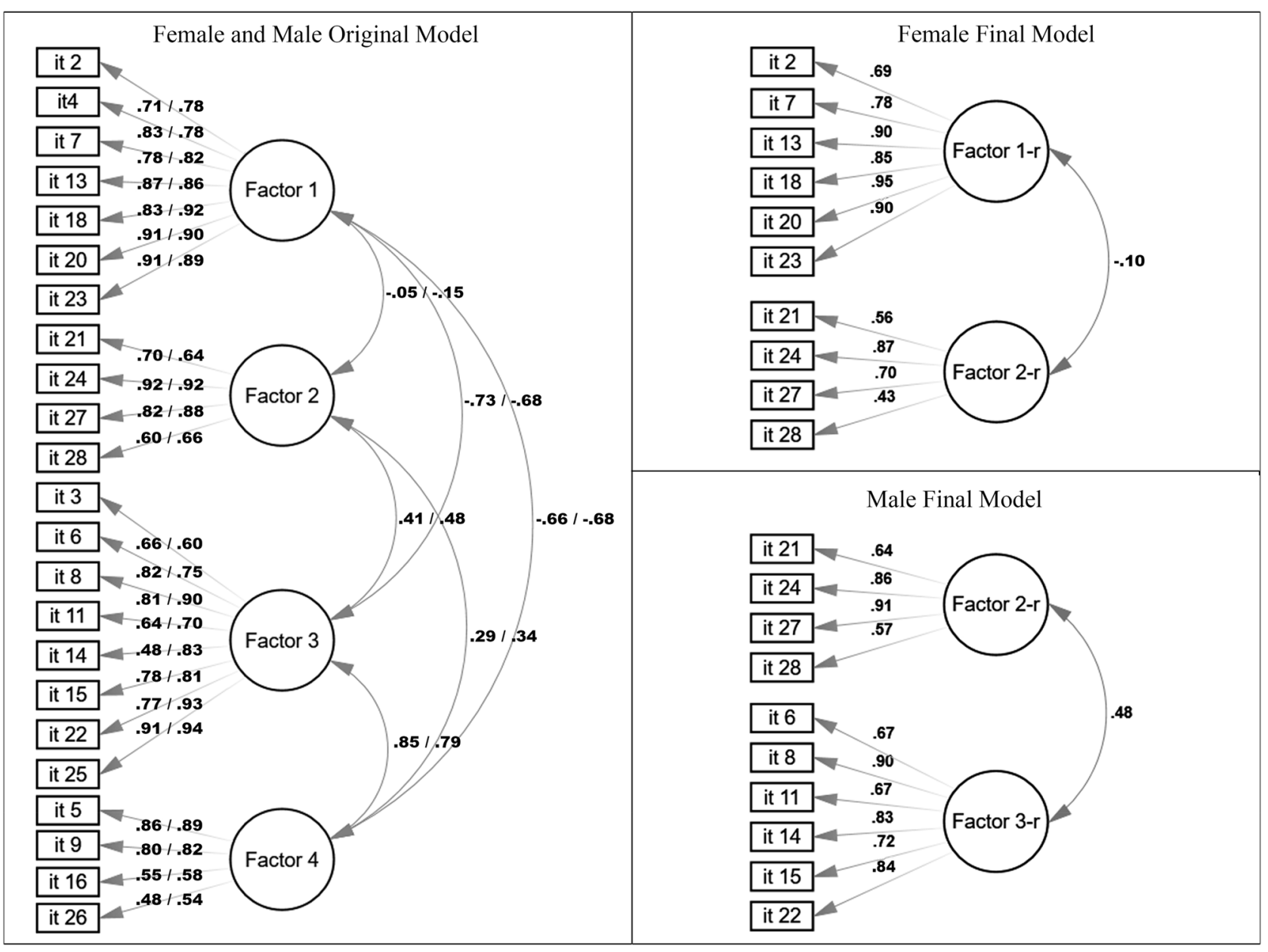

Fig. 1 Representation of the instrument evaluated considering original and final models. Note it $=$ item, Factor $1=$ Dissatisfaction and fat, Factor $2=$ External parts, Factor $3=$ Satisfaction and muscle, Factor $4=$ Lower parts, Factor $1-r=$ Satisfaction with body and fat, Factor $2-r=$ Satisfaction with body external parts, Factor 3-r $=$ Satisfaction with body and muscle. Values represent items' factorial weights and correlations between factors. For the original model, values are presented for both female (first value) and male (second value) samples

\section{Measure}

The ESSC was proposed in the Brazilian context to assess body satisfaction [16]. In the original study, a set of 33 items was initially developed; however, some items were excluded, and the initial item numbering was maintained. Thus, the final version of the instrument presented in the article consisted of 23 items (nine reversed items: 2, 4, 7, 13, 16, 18, 20, 23, and 26) with 5-point Likert response scale ( $1=$ strongly disagree to $5=$ strongly agree $)$. The factorial model of the ESSC was presented with four factors, namely F1 = "Dissatisfaction and Fat", F2 = "External Parts", F3 = "Satisfaction and Muscle", and F4 = "Lower Parts". In the original study, the authors reported acceptable values of the internal consistency for ESSC factors (alpha de Cronbach $[\alpha]=0.65-0.82$ ) and a good ability to discriminate groups of men and women satisfied with their body $(p<0.001)$. 


\section{Procedure and ethical aspects}

The recruitment process of the participants was non-probabilistic. First, the study was released by e-mail and social media (e.g., Facebook and Instagram) among students, staff, and professors of São Paulo State University (UNESP, campus Araraquara). Those individuals who are interested in the study received information about the purpose of the research. In sequence, the individuals were asked to share the research with other people (e.g., family members and peers). Thus, we used a snowball non-random sampling for data collection. Those who agreed to participate and met the inclusion criteria signed an informed consent form and completed the Portuguese paper-and-pencil version of the ESSC and the other questions to characterize the sample. Participants provided the data in a room at the university designed for the research, which accommodated at the same time five people - each in an armchair. When the participant finished filling out the questionnaire, he/she handed it to the researcher outside the room.

Ethics approval was obtained from the Human Research Ethics Committee of the School of Dentistry (UNESP, campus Araraquara), with protocol number 88600318.3.0000.5416.

\section{Data analysis}

The psychometric sensitivity of the ESSC items was evaluated by the skewness and kurtosis absolute values. The estimates lower than 3 and 7, respectively, were used as parameters of adequate psychometric sensitivity.

The construct validity of the original ESSC model (i.e., 23 items and four factors) was assessed based on the factorial, convergent, and discriminant validity. These analyses were performed separately for women and men using half of the total sample obtained for each sex.

Factorial validity was evaluated by confirmatory factor analysis (CFA) using Weighted Least Squares Mean and Variance Adjusted (WLSMV) estimator for the polychoric correlation matrix. In CFA, the goodness-of-fit indices used were chi-squared by degrees of freedom ratio $\left(\chi^{2} / d f\right)$, Comparative Fit Index (CFI), Tucker-Lewis Index (TLI), Weighted Root Mean Square Residual (WRMR), and Root Mean Square Error of Approximation (RMSEA) with $90 \%$ confidence interval. Values of the $\chi^{2} / d f \leq 5.0, \mathrm{CFI} \geq 0.90$, $\mathrm{TLI} \geq 0.90, \mathrm{WRMR}<1.0$, and RMSEA $\leq 0.10$ were considered acceptable for model fit [18, 24, 25]. Furthermore, the standardized factorial weight $(\lambda)$ of each item was evaluated and values $\geq 0.40$ were considered adequate. To fit the model, the modification indices $>11$, calculated from Lagrange Multipliers (LM), were analyzed [18, 26].
Convergent validity was evaluated by the average variance extracted (AVE) that was calculated for each factor of the ESSC. Values of AVE $\geq 0.50$ were considered adequate [27].

Discriminant validity was evaluated by the coefficients of determination (i.e., square correlation $\left[r^{2}\right]$ of two correlated factors) and AVE values. When values of the AVE for each pair of correlated factors were $\geq r^{2}$, there was discriminant validity $[18,27]$.

We also estimate the reliability of the ESSC factors. For that, the composite reliability (CR), the ordinal alpha coefficient $(\alpha)$, and the omega coefficient $(\omega)$ were calculated. Values $\geq 0.70$ in all indices indicated good reliability [18, 28].

Furthermore, we evaluated the factorial invariance of the original model across sexes. For that, multi-group analysis using the CFI difference ( $\Delta \mathrm{CFI}$ ) was used. The results were evaluated in levels to compare CFI values of the configural $(\lambda)$, metric (thresholds), and scalar (residuals) models. The invariance was considered strong when the CFI reduction was lower than - 0.01 among the models [29]. As the ESSC original model did not fit the data, a fitted model for each sex was investigated. Final models were confirmed in independent samples (i.e., using the other half of the total sample obtained for each sex).

After determining the model with the best fit for each sample, the mean score for each factor of the instrument was calculated separately for women and men using the percentiles $(\mathrm{P})$ of the response scale as follows: $1.0 H 2.0$ $(\mathrm{P} \leq 25)=$ not at all satisfied; $2.0-3.0(\mathrm{P} 25-\mathrm{P} 50)=$ slightly satisfied; 3.0- 4.0 (P50- 75) = moderately satisfied; $4.0-15.0$ $(\mathrm{P}>75)=$ very satisfied. We also estimated the prevalence of each factor with $95 \%$ CI. It is important to clarify that the negative items were inverted before the final score was calculated.

IBM SPSS Statistics v. 22 (SPSS, an IMB Company, Chicago, IL, USA), MPLUS v. 7.2 (Muthén and Muthén, Los Angeles, CA, USA) and R v. 3.6.2 (R Core Team, 2019) were used to perform the analyses.

\section{Results}

A total of 1,481 individuals participated in the study (women $=1,035 ;$ men $=446)$. Their mean age was 25.2 (standard deviation $[\mathrm{SD}]=5.9$ ) years old for the female sample and $24.9(\mathrm{SD}=5.6)$ years old for the male sample. The BMI mean values for women and men were 24.0 $(\mathrm{SD}=4.6)$ $\mathrm{kg} / \mathrm{m}^{2}$ and $25.1(\mathrm{SD}=4.8) \mathrm{kg} / \mathrm{m}^{2}$, respectively. Table 1 presents the characteristics of the sample.

No item of the instrument showed discrepant values for skewness $(>|3|)$ or kurtosis $(>|7|)$ attesting to adequate psychometric sensitivity. Table 2 presents the psychometric indicators of the original model of the instrument (i.e., 
Table 1 Characteristics of the sample

\begin{tabular}{|c|c|c|}
\hline & \multicolumn{2}{|c|}{ Sample $n(\%)$} \\
\hline & Female & Male \\
\hline \multicolumn{3}{|l|}{ Marital status } \\
\hline Single & $790(76.6)$ & $378(85.1)$ \\
\hline Married & $210(20.4)$ & $64(14.4)$ \\
\hline Divorced & $30(2.9)$ & $2(.5)$ \\
\hline Widowed & $1(.1)$ & - \\
\hline \multicolumn{3}{|l|}{ Race } \\
\hline Asian & $16(1.6)$ & $12(2.7)$ \\
\hline White & $756(73.6)$ & $315(71.3)$ \\
\hline Mixed & $190(18.5)$ & $89(20.2)$ \\
\hline Black & $65(6.3)$ & $26(5.8)$ \\
\hline \multicolumn{3}{|l|}{ Physical activity practice } \\
\hline No & $497(48.2)$ & $134(30.3)$ \\
\hline Yes & $535(51.8)$ & $308(69.7)$ \\
\hline \multicolumn{3}{|l|}{ Frequency of physical activity by days of the week } \\
\hline$<3$ & $144(26.9)$ & $66(21.4)$ \\
\hline $3 H 5$ & $338(63.2)$ & $206(66.9)$ \\
\hline$\geq 5$ & $53(9.9)$ & $36(11.7)$ \\
\hline \multicolumn{3}{|l|}{ Aesthetic procedure to change the body } \\
\hline No & $875(85.1)$ & $413(93.0)$ \\
\hline Yes & $153(14.9)$ & $31(7.0)$ \\
\hline \multicolumn{3}{|l|}{ Educational level } \\
\hline Incomplete elementary school & $25(2.4)$ & $16(3.6)$ \\
\hline Elementary school diploma/incomplete junior high school & $58(5.6)$ & $30(6.7)$ \\
\hline Junior high school diploma/incomplete high school & $108(10.5)$ & $38(8.5)$ \\
\hline High school diploma/incomplete higher education & $383(37.3)$ & $158(35.5)$ \\
\hline Higher education degree & $453(44.2)$ & $203(45.7)$ \\
\hline \multicolumn{3}{|l|}{ Weight status } \\
\hline Underweight & $40(3.9)$ & $12(2.8)$ \\
\hline Normal weight & $646(63.8)$ & $244(56.2)$ \\
\hline Overweight & $220(21.7)$ & $126(29.0)$ \\
\hline Obesity & $107(10.6)$ & $52(12.0)$ \\
\hline \multicolumn{3}{|l|}{ Economic class (average household income USD) } \\
\hline A $(4902.70)$ & $231(25.3)$ & $122(30.7)$ \\
\hline B (1623.16) & $489(53.6)$ & $200(50.3)$ \\
\hline $\mathrm{C}(463.72)$ & $183(20.0)$ & $74(18.6)$ \\
\hline D-E (138.10) & $10(1.1)$ & $2(.4)$ \\
\hline
\end{tabular}

The average household income (Brazilian Criteria 2019) in Brazilian reals was converted (exchange rate in April 2020) into American dollars (https://www.bcb.gov.br/conversao) complete with four factors) for female and male samples and Fig. 1 presents the factorial weights.

The original model did not adequately fit the samples (see Table 1). The modification indices indicated many correlations between errors for items in both samples (ML range $=11.02-384.69$ ). On the other hand, all factor weights of the items were $\geq 0.48$. The multi-group analysis made across sexes showed invariance of the ESSC original model $(\Delta \mathrm{CFI}$ : metric model - configural model $=0$; scalar model - metric model $=-0.01)$. To improve the model fit, some modifications were made. For the female sample, items \#14 (I am satisfied with my chest) and \#26 (I think I have too much cellulite) were deleted, as both had high covariance with the other items and factors. A correlation was also allowed between errors for items \#8 (In general, I am satisfied with my muscle definition) and 22 (In general, I am satisfied with the size of my muscles) because they had $\mathrm{ML}=132.35$ and similar content. With this refinement, the model presented better fit (see Table 2, refined complete model for female sample 1). For the male sample, 


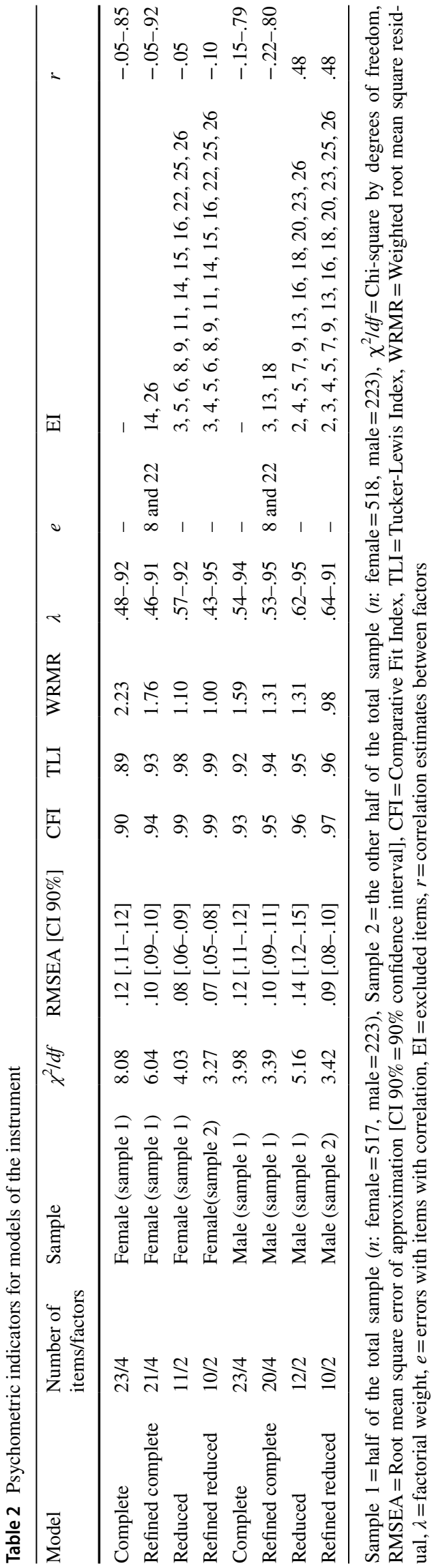

a refinement of the model was also needed. Items \#3 (I am satisfied with the thickness of my arms), \#13 (If I was thinner, I would feel much better), and \#18 (I am unhappy with my abdomen) showed high covariance with many items and different factors; therefore, they were excluded. A correlation between errors for items 8 and $22(\mathrm{ML}=17.51)$ was also allowed due to similar content. After these modifications, the refined model presented better fit (see Table 2, refined complete model for male sample 1).

Tables 3 and 4 present estimates of convergent and discriminant validity and reliability of the instrument. Both the complete and refined models presented adequate convergent validity and good reliability for female and male samples; however, factor 4 did not attained good parameters in the female sample. Moreover, the discriminant validity was compromised between one pair of factors (F3 vs. F4) for both samples.

Thus, we conducted a theoretical investigation of the instrument based on social and positive psychology perspectives on human appearance [1], seeking to identify the most adequate model. This strategy aimed to build a model that is not based only on results of statistical tests, but on the underlying theory of the evaluated construct. In this way, we found specific contents for each sex. Thus, we decided to build a model for each sex. For women, we selected factors 1 (Dissatisfaction and Fat) and 2 (External Parts), and for men, we selected factors 2 and 3 (Satisfaction and Muscle). Factor 4 (Lower Parts) was not included in the male model because we did not find solid theoretical evidence to support it to assess men's body satisfaction/dissatisfaction. The items of factor 4 seem to be more targeted at women; however, the content was already addressed in other items; therefore, this factor was not included in the female model. The constructed models were identified as reduced models, since they were composed of only two factors.

In the reduced model proposed for the female sample, errors for items \#2 (I would like to change many things on my body) and \#4 (I feel ashamed of my body) were highly correlated $(\mathrm{ML}=24.19)$ and even after inserting a covariance, the model fit did not show a satisfactory improvement. Thus, we opted to exclude item 4 because it has content related to "shame" and not "body dissatisfaction". After this modification, the final female model (see Fig. 1) was confirmed in an independent sample and showed a good fit of the data (see Table 2, refined reduced model for female sample 2).

In the reduced model proposed for the male sample, items \#3 (I am satisfied with the thickness of my arms) and \#25 (I am satisfied with my body) were excluded due to high correlations with other items and different factors (ML range $=13.00-87.33$ ). Moreover, item 25 presented content without specificity (i.e., assessing satisfaction with the body as a whole) contributing to its exclusion. Thus, the final male 
Table 3 Estimates of the convergent and discriminant validity

\begin{tabular}{|c|c|c|c|c|c|c|c|}
\hline \multirow[t]{2}{*}{ Model } & \multirow{2}{*}{$\begin{array}{l}\text { Number of } \\
\text { items/factors }\end{array}$} & \multirow[t]{2}{*}{ Sample } & \multicolumn{5}{|c|}{$\mathrm{AVE} / r^{2}$} \\
\hline & & & & $\mathrm{F} 1$ & $\mathrm{~F} 2$ & F3 & F4 \\
\hline \multirow[t]{4}{*}{ Complete } & \multirow[t]{4}{*}{$23 / 4$} & \multirow[t]{4}{*}{ Female (sample 1) } & $\mathrm{F} 1$ & .70 & .00 & .53 & .43 \\
\hline & & & $\mathrm{F} 2$ & - & .58 & .17 & .09 \\
\hline & & & F3 & - & - & .56 & .72 \\
\hline & & & $\mathrm{F} 4$ & - & - & - & .48 \\
\hline \multirow[t]{4}{*}{ Refined complete } & \multirow[t]{4}{*}{$21 / 4$} & \multirow[t]{4}{*}{ Female (sample 1) } & $\mathrm{F} 1$ & .70 & .00 & .56 & .43 \\
\hline & & & $\mathrm{F} 2$ & - & .59 & .16 & .12 \\
\hline & & & F3 & - & - & .57 & .84 \\
\hline & & & $\mathrm{F} 4$ & - & - & - & .52 \\
\hline \multirow[t]{2}{*}{ Reduced } & \multirow[t]{2}{*}{$11 / 2$} & \multirow[t]{2}{*}{ Female (sample 1) } & $\mathrm{F} 1$ & .69 & .01 & - & - \\
\hline & & & $\mathrm{F} 2$ & - & .56 & - & - \\
\hline \multirow[t]{2}{*}{ Refined reduced } & \multirow[t]{2}{*}{$10 / 2$} & \multirow[t]{2}{*}{ Female (sample 2) } & F1-r & .72 & .01 & - & - \\
\hline & & & $\mathrm{F} 2-\mathrm{r}$ & - & .50 & - & - \\
\hline \multirow[t]{4}{*}{ Complete } & \multirow[t]{4}{*}{$23 / 4$} & \multirow[t]{4}{*}{ Male (sample 1) } & $\mathrm{F} 1$ & .73 & .02 & .47 & .46 \\
\hline & & & $\mathrm{F} 2$ & - & .62 & .23 & .12 \\
\hline & & & F3 & - & - & .67 & .62 \\
\hline & & & $\mathrm{F} 4$ & - & - & - & .52 \\
\hline \multirow[t]{4}{*}{ Refined complete } & \multirow[t]{4}{*}{$20 / 4$} & \multirow[t]{4}{*}{ Male (sample 1) } & $\mathrm{F} 1$ & .68 & .05 & .54 & .50 \\
\hline & & & $\mathrm{F} 2$ & - & .62 & .19 & .12 \\
\hline & & & F3 & - & - & .69 & .64 \\
\hline & & & $\mathrm{F} 4$ & - & - & - & .52 \\
\hline \multirow[t]{2}{*}{ Reduced } & \multirow[t]{2}{*}{$12 / 2$} & \multirow[t]{2}{*}{ Male (sample 1) } & $\mathrm{F} 2$ & - & .72 & .23 & - \\
\hline & & & $\mathrm{F} 3$ & - & - & .66 & - \\
\hline \multirow[t]{2}{*}{ Refined reduced } & \multirow[t]{2}{*}{$10 / 2$} & \multirow[t]{2}{*}{ Male (sample 2) } & $\mathrm{F} 2-\mathrm{r}$ & - & .58 & .23 & - \\
\hline & & & F3-r & - & - & .60 & - \\
\hline
\end{tabular}

Sample $1=$ half of the total sample $(n$ : female $=517$, male $=223)$, Sample $2=$ the other half of the total sample $(n$ : female $=518$, male $=223)$, AVE $=$ values in the diagonal are estimates of the average variance extracted, $r^{2}=$ determination coefficient. Factors of the original scale: F1=Dissatisfaction and fat, F2 $=$ External Parts, F3 = Satisfaction and muscle, F4=Lower parts. Factors of the scale with two factors: $\mathrm{F} 1-\mathrm{r}=$ Satisfaction with body and fat, F2-r=Satisfaction with body external parts, F3-r = Satisfaction with body and muscle model (see Fig. 1) was confirmed in an independent sample and showed a good fit of the data (see Table 2, refined reduced model for male sample 2).

Convergent and discriminant validity were adequate for two-factor models in both samples (see Table 3, refined reduced models). Furthermore, all values of $\mathrm{CR}, \alpha$, and $\omega$ were adequate, attesting the reliability of the two-factor models (see Table 4, refined reduced models).

After the fit of the refined reduced models to the samples, we identified the need to modify some terms in the instrument. The term "situational" was removed in the name of the scale and the terms female (Female Body Satisfaction Scale [BSS-F]) and male (Male Body Satisfaction Scale [BSS-M]) were added. The term "situational" was excluded because the scale did not have items that assessed body satisfaction considering specific situations, such as "If I were thinner, I would feel much better wearing a bathing suit on the beach". We also changed the name of the factors to clarify the content of the item set and to facilitate the interpretation of the score. Thus, the "Dissatisfaction and Fat" factor was renamed to "Satisfaction with Body and Fat". The "External Parts" factor was renamed to "Satisfaction with Body External Parts". The "Satisfaction and Muscle" factor was renamed to "Satisfaction with Body and Muscle". Note that, before using the results of the female model (BSS-F), the responses of items \#2, \#7, \#13, \#18, \#20 and \#23 must be inverted (e.g., if an individual to mark "strongly agree" [5 points) for the item \#2, the answer must be recoded to "strongly disagree" [1 point]). Thus, for both female and male reduced model, the higher the score, the greater the individual's body satisfaction. In addition, we named all points of the 5-point Likert response scale ( $1=$ strongly disagree, 2 = disagree, $3=$ neither agree nor disagree, $4=$ agree, $5=$ strongly agree). This will better direct the participant to complete the instrument. Table 5 presents the English and Portuguese versions of the scale for each sex considering the fitted final models. 
Table 4 Reliability estimates

\begin{tabular}{|c|c|c|c|c|c|c|}
\hline Model & $\begin{array}{l}\text { Number of items/ } \\
\text { factors }\end{array}$ & Sample & Factor & CR & $\alpha$ & $\omega$ \\
\hline \multirow[t]{4}{*}{ Complete } & \multirow[t]{4}{*}{$23 / 4$} & \multirow[t]{4}{*}{ Female (sample 1) } & $\mathrm{F} 1$ & .94 & .94 & .73 \\
\hline & & & $\mathrm{F} 2$ & .85 & .84 & .80 \\
\hline & & & F3 & .91 & .90 & .88 \\
\hline & & & $\mathrm{F} 4$ & .77 & .69 & .73 \\
\hline \multirow[t]{4}{*}{ Refined complete } & \multirow[t]{4}{*}{$21 / 4$} & \multirow[t]{4}{*}{ Female (sample 1) } & $\mathrm{F} 1$ & .94 & .94 & .74 \\
\hline & & & $\mathrm{F} 2$ & .85 & .84 & .81 \\
\hline & & & $\mathrm{F} 3$ & .90 & .90 & .86 \\
\hline & & & $\mathrm{F} 4$ & .75 & .65 & .71 \\
\hline \multirow[t]{2}{*}{ Reduced } & \multirow[t]{2}{*}{$11 / 2$} & \multirow[t]{2}{*}{ Female (sample 1) } & $\mathrm{F} 1$ & .93 & .93 & .76 \\
\hline & & & $\mathrm{F} 2$ & .84 & .84 & .80 \\
\hline \multirow[t]{2}{*}{ Refined reduced } & \multirow[t]{2}{*}{$10 / 2$} & \multirow[t]{2}{*}{ Female (sample 2) } & F1-r & .94 & .93 & .76 \\
\hline & & & F2-r & .74 & .72 & .70 \\
\hline \multirow[t]{4}{*}{ Complete } & \multirow[t]{4}{*}{$23 / 4$} & \multirow[t]{4}{*}{ Male (sample 1) } & $\mathrm{F} 1$ & .95 & .94 & .80 \\
\hline & & & $\mathrm{F} 2$ & .86 & .83 & .82 \\
\hline & & & $\mathrm{F} 3$ & .94 & .93 & .93 \\
\hline & & & $\mathrm{F} 4$ & .81 & .73 & .78 \\
\hline \multirow[t]{4}{*}{ Refined complete } & \multirow[t]{4}{*}{$20 / 4$} & \multirow[t]{4}{*}{ Male (sample 1) } & $\mathrm{F} 1$ & .91 & .90 & .75 \\
\hline & & & $\mathrm{F} 2$ & .86 & .83 & .82 \\
\hline & & & F3 & .94 & .94 & .92 \\
\hline & & & $\mathrm{F} 4$ & .80 & .73 & .77 \\
\hline \multirow[t]{2}{*}{ Reduced } & \multirow[t]{2}{*}{$12 / 2$} & \multirow[t]{2}{*}{ Male (sample 1) } & $\mathrm{F} 2$ & .95 & .93 & .93 \\
\hline & & & F3 & .94 & .86 & .92 \\
\hline \multirow[t]{2}{*}{ Refined reduced } & \multirow[t]{2}{*}{$10 / 2$} & \multirow[t]{2}{*}{ Male (sample 2) } & F2-r & .84 & .83 & .79 \\
\hline & & & F3-r & .90 & .89 & .88 \\
\hline
\end{tabular}

Sample $1=$ half of the total sample (n: female $=517$, male $=223$ ), Sample $2=$ the other half of the total sample ( $\mathrm{n}$ : female $=518$, male $=223$ ), $C R=$ composite reliability, $\alpha=$ ordinal alpha coefficient, $\omega=$ omega coefficient. Factors of the original scale: F1 = Dissatisfaction and Fat, F2=External Parts, F3=Satisfaction and Muscle, F4 = Lower Parts. Factors of the scale with two factors: F1-r = Satisfaction with Body and Fat, F2-r = Satisfaction with Body External Parts, F3-r= Satisfaction with Body and Muscle

Considering the final models, the mean score for the female sample was $2.83(\mathrm{SD}=1.27)$ for "Satisfaction with Body and Fat" factor and $3.52(\mathrm{SD}=1.01)$ for "Satisfaction with Body External Parts" factor. The male sample registered $3.66(\mathrm{SD}=1.01)$ for "Satisfaction with Body External Parts" factor and $3.04(\mathrm{SD}=1.04)$ for "Satisfaction with Body and Muscle" factor. Figure 2 presents the prevalence of individuals classified according to mean scores for final models separately for women and men.

The majority of women (38.2\% [CI 95\% 35.2-41.0]) and men (37.7\% [CI 95\% 33.0-42.2]) were moderately satisfied with body external parts and this prevalence was equal for both sexes. Most women (33.9\% [CI 95\% 30.9-37.0]) were not at all satisfied with their body and fat and the most men (32.3\% [CI 95\% 27.4-36.5]) were slightly satisfied with body and muscle.

\section{Discussion}

This study presents data on the factorial model of an instrument (ESSC) developed to assess body satisfaction in Brazilian samples. Our results indicated that the four-factor model and twenty-three items were not the most appropriate for the samples. Refined complete models presented acceptable factorial and convergent validity, but discriminant validity was poor. Thus, a reduced model for each sex was built and these structures showed better psychometric indicators.

Considering the importance of psychometrically evaluating the ESSC - since it was never evaluated beyond the original study [16] —our first analytical step was to investigate the factorial validity of this instrument. In this analysis, we observed that the complete model did not fit data, thus revealing the poor validity. To fit the model, we used modification indices and observed the existence of many co-variances between item errors. This means that the contents of the items were highly related, which impaired the fit of the instrument. Even after refinement, the discriminant 

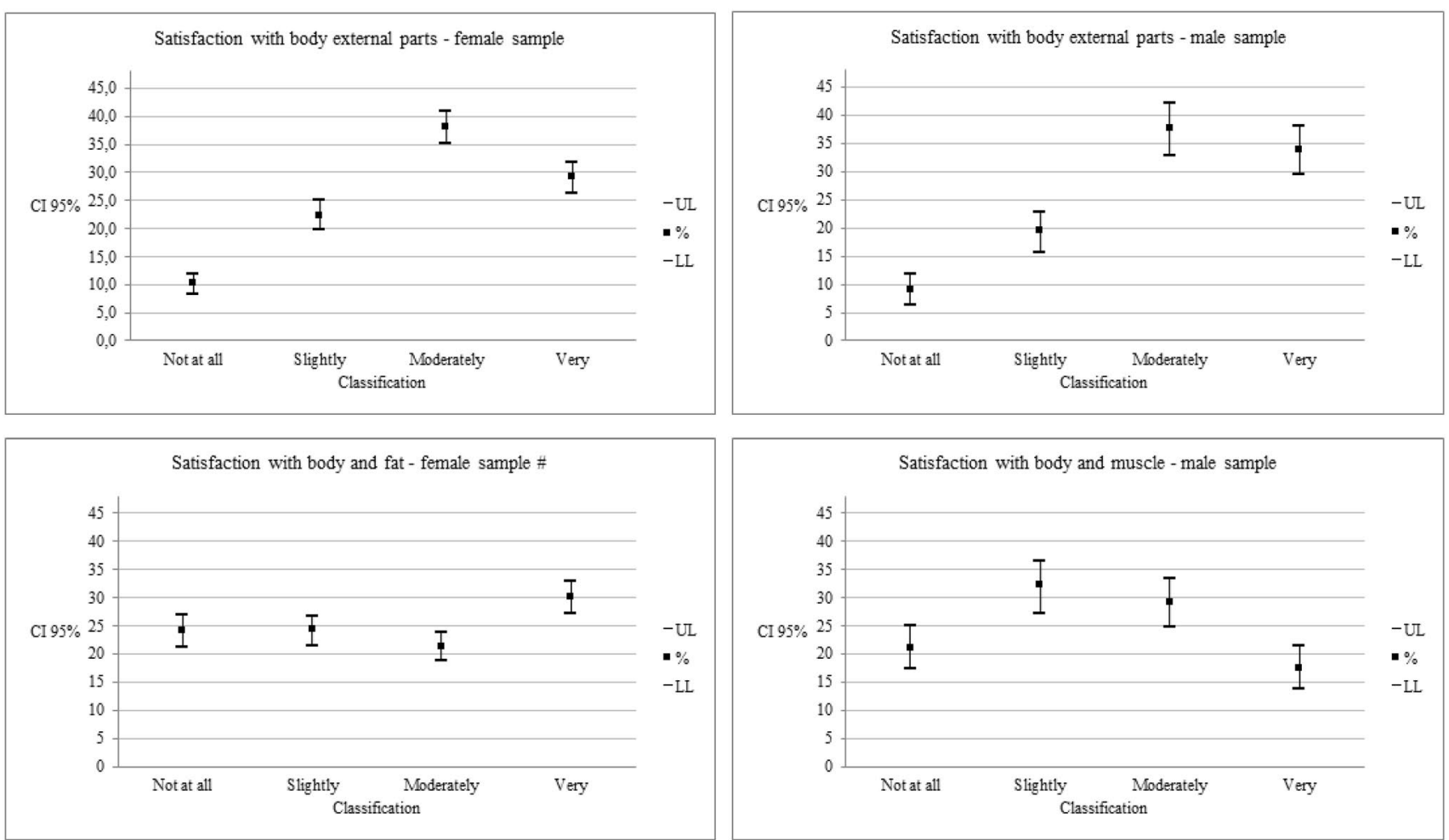

Fig. 2 Classification of individuals according to the mean scores for reduced versions of the instrument. Note CI 95\% $=95 \%$ confidence interval, $\mathrm{UL}=$ Upper limit, $\mathrm{LL}=$ Lower limit, Not at all $=$ mean score among 1.0 and 2.0 points, Slightly=mean score among 2.0 and 3.0

validity of the models was poor. This result shows that the items of one factor were saturating in another factor, which aroused the need for a theoretical review of the instrument.

For the theoretical investigation, the literature was consulted to verify which body aspects are more important for each sex. Studies $[5,8]$ indicate that the ideal body types highly valued by women are thin and shapely. On the other hand, men define the ideal body as muscular, valuing the upper body (e.g., shoulders) as areas that affect their body satisfaction [12]. Furthermore, we found women and men's perception of their face as attractive, including hair, may influence overall satisfaction with the body [30, 31]. From this information, we build a reduced model for each sex. We decided to include only two factors for each model aiming to provide the clinical and academic community an instrument with greater feasibility of application, that is, that would capture body satisfaction using few items. However, even after using only two factors, some items did not contribute to the fit of the models; therefore, they were deleted. For example, item four was excluded because of its content, since people who experienced body shame do not simply feel dissatisfied with their bodies. They feel contemptuous of their body and wants to change it at any cost [1, 32, 33]. After modifications, refined reduced models showed adequate estimates of validity and reliability; therefore, they

points, moderately $=$ mean score among 3.0 and 4.0 , very $=$ mean score among 4.0 and 5.0 points. "In this factor (Satisfaction with body and fat-female sample) the values of the responses given to the all items were inverted before calculation of the mean score

were considered the most appropriate for the data. However, it is important to emphasize that these models must be applied in other Brazilian contexts to verify the fit in other samples to support the adequacy of these structures.

In the last stage of our study, we identified the level of body satisfaction among the participants. Interestingly, both sexes were more satisfied with their hair, face, skin, and body hair. This finding may suggest that these items were not the target of participants' concerns, perhaps because they can be changed through aesthetic procedures and the use of cosmetics [34]. In other words, Brazilian men and women could value more body size and shape than face and hair. Petrie and colleagues [30] reported that American students were more satisfied with their faces than with their bodies. This result corroborates our findings.

Still, our results showed that most women and men had low body satisfaction, which corroborates the literature [3, $5,7,9,10]$. More specifically, our findings demonstrated that women were not at all satisfied with their amount of fat, and men were slightly satisfied with their muscles. This represents an alert for the development of dysfunctional behaviors, such as restrictive dieting, heavyweight lifting, and taking supplements to lose or gain weight. As a consequence, these behaviors can trigger mental disorders, 
such as anorexia nervosa, bulimia nervosa as well as the development of anxiety and depression. Griffiths and colleagues [10] examined the relationship between body dissatisfaction and health-related quality of life in Australian women and men. They found increased levels of body dissatisfaction among participants and a significant association of this concept with poorer mental and physical health. Therefore, high levels of body dissatisfaction may threaten people's psychological and physical well-being.

\section{What is already known on this subject?}

Researchers and clinicians have been looking for psychometrically appropriate measures to understand the mental representation that people build of their own body (i.e., body image). A body satisfaction scale developed in Brazilian context can be useful for this purpose; however, its validity has never been tested.

\section{What this study adds?}

We found that the complete version of the Brazilian measure was not valid and reliable for the data. Therefore, we fitted the instrument to samples and found a reduced model for each sex that can to help researchers and clinicians-who aim to assess individuals' body satisfaction - to develop protocols to reduce body dissatisfaction.

\section{Limitations}

Although the present study has implications about the use of the measure to assess body satisfaction, some limitations should be highlighted. First, we used a self-reported measure, which can produce inexact data if participants do not respond with due attention; because of this limitation, we sought to use a large sample to reduce this bias. Second, our sample was mostly female and this may reflect the fact that women are more likely to participate in studies than men; however, the sample size used for the male sample was adequate to perform the analyses. Third, the non-probabilistic sample and limited age limit the generalization of our results to other population groups. Fourth, our study design was cross-sectional, which does not permit us to infer a cause-and-effect relationship. Fifth, we do not use additional measures to assess the external validity of the scale, nor an exploratory factor analysis to investigate the dimensionality of the instrument (i.e., based only on statistical grounds). Nevertheless, our results might be useful for future studies that aim to use body satisfaction scales.

\section{Clinical implications}

Developing specific measures to assess the elements of body image is relevant. However, such measures need to have good indicators of validity and reliability of the data collected. We found that the model originally proposed for the ESSC did not produce good psychometric indicators for Brazilian samples. Therefore, the use of this model in samples with characteristics similar to ours will probably produce inaccurate results. With the reduced models (BSS-F and BSS-M), researchers and clinicians might be able to assess more appropriately the body satisfaction of young women and men. However, this will only be possible if the context of application is similar to that of the sample in the present study. This evaluation is an important step for clinicians to understand and work effectively with patients who experience poorer body satisfaction. Nutritionists, psychologists, doctors, and other health professionals can work to counter negative messages related to body image aiming to encourage a healthy lifestyle that includes moderate exercise, nutritious eating, and body acceptance, because collaborative treatment involves a multidisciplinary team. Furthermore, clinicians should keep in mind that social predictors (e.g., media and peers) continually reinforce the desirability of the ideal body. An individual's psychological knowledge can be useful in trying to reduce body dissatisfaction and promote positive body image for women and men.

\section{Conclusion}

Our study presented psychometric indicators of an instrument developed to assess body satisfaction in the Brazilian context (ESSC). The original factorial model of the instrument did not fit data and a new structure was investigated. A reduced model for women (BSS-F) and another for men (BSS-M) were found and fitted to samples. These models showed adequate indices of factorial, convergent and discriminant validity, and good reliability for samples. Furthermore, we found that most participants were not very satisfied with their bodies, with women being more dissatisfied with the amount of fat and men with their musculature. These findings may be useful for psychometric, epidemiological, and clinical literature regarding the presentation of models with good estimates of validity and reliability to investigate the population's body satisfaction.

Acknowledgements We thank the School of Pharmaceutical Sciences of São Paulo State University (UNESP, Campus of Araraquara/SP) for institutional support. Further, we are grateful to Arthur Ragazzi, Patrícia Teixeira, and Lucas Campos for their contribution to data collection.

Author contributions Material preparation, data collection and analysis were performed by Wanderson R. da Silva. The first draft of the manuscript was written by Wanderson R. da Silva and the other authors commented on previous versions of the manuscript. All authors read and approved the final manuscript. 
Funding The study was financially supported in part by the São Paulo Research Foundation (grants \#2017/20315-7, \#2019/19590-9).

Availability of data and material The datasets generated and analyzed during the current study are available from the corresponding author on reasonable request.

Code availability Not applicable.
Ethics approval The Human Research Ethics Committee of the São Paulo State University (UNESP) of School of Dentistry approved the study (ethics approval number: 88600318.3.0000.5416).

Consent to participate Informed consent was obtained from all individual participants included in the study.

Consent for publication Not applicable.

\title{
Compliance with ethical standards
}

Conflict of interest The authors declare that they have no conflict of interest.

\section{Appendix}

\author{
See Table 5 .
}

Table 5 Brazilian Portuguese and English versions of the Body Satisfaction Scale for each sex

English\# Portuguese

Female Body Satisfaction Scale (BSS-F)

Instruction: Answer the statements below according to your opinion at the moment

Response Options: $1=$ strongly disagree, $2=$ disagree, $3=$ neither agree or disagree, $4=$ agree, $5=$ strongly agree

(2) I would like to change many things about my body

(7) I am unhappy with my waist

(13) If I was thinner, I would feel much better

(18) I am unhappy with my belly

(20) I think I have too much fat on my body

(23) I am unhappy with my body measurements

(21) I am satisfied with my hair

(24) I am satisfied with my face

(27) I am satisfied with my skin

(28) I am satisfied with the amount of hair I have on my body

Male Body Satisfaction Scale (BSS-M)

Instruction: Answer the statements below according to your opinion

Response Options: $1=$ strongly disagree, $2=$ disagree, $3=$ neither agree or disagree, $4=$ agree, $5=$ strongly agree

(21) I am satisfied with my hair

(24) I am satisfied with my face

(27) I am satisfied with my skin

(28) I am satisfied with the amount of hair I have on my body

(6) I like my current body weight

(8) In general, I am satisfied with my muscle definition

(11) I like the width of my shoulders

(14) I am satisfied with my chest

(15) I think my body is attractive

(22) In general, I am satisfied with the size of my muscles
Escala Feminina de Satisfação Corporal (ESC-F)

Instrução: Responda as afirmações abaixo de acordo com a sua opinião neste momento

Opções de resposta: 1 = discordo totalmente, 2 = discordo, 3 = não concordo ou discordo, $4=$ concordo, $5=$ concordo totalmente)

(2) Gostaria de mudar muitas coisas no meu corpo

(7) Estou descontente com a minha cintura

(13) Se eu estivesse mais magra, me sentiria muito melhor

(18) Estou descontente com a minha barriga

(20) Acho que tenho gordura demais no meu corpo

(23) Estou descontente com as minhas medidas corporais

(21) Estou satisfeita com os meus cabelos

(24) Estou satisfeita com o meu rosto

(27) Estou satisfeita com a minha pele

(28) Estou satisfeita com a quantidade de pelos que tenho no corpo Escala Masculina de Satisfação Corporal (ESC-M)

Instrução: Responda as afirmações abaixo de acordo com a sua opinião Opções de resposta: $1=$ discordo totalmente, 2 = discordo, $3=$ não concordo ou discordo, $4=$ concordo, $5=$ concordo totalmente

(21) Estou satisfeito com os meus cabelos

(24) Estou satisfeito com o meu rosto

(27) Estou satisfeito com a minha pele

(28) Estou satisfeito com a quantidade de pelos que tenho no corpo

(6) Gosto do peso que tenho agora

(8) De modo geral, estou satisfeito com a minha definição muscular

(11) Gosto da largura dos meus ombros

(14) Estou satisfeito com o meu peitoral

(15) Acho meu corpo atraente

(22) De modo geral, estou satisfeito com o tamanho dos meus músculos

\#The cross-cultural adaptation of the scale for the English language was performed following international guidelines to guarantee idiomatic, conceptual, and semantic equivalences. Satisfaction with Body and Fat: items 2, 7, 13, 18, 20 and 23. Satisfaction with Body External Parts: items 21, 24, 27 and 28. Satisfaction with Body and Muscle: items 6, 8, 11, 14, 15 and 22. The numbering of the items on the instrument was maintained according to the proposal originally developed by Hirata and Pilati in 2010. [Fator "Satisfação com o Corpo e Gordura": itens 2, 7, 13, 18, 20 e 23. Fator "Satisfação com as partes externas do corpo": itens 21, 24, 27 e 28. Fator "Satisfação com o corpo e músculo": itens 6, 8, $11,14,15$ e 22. A numeração dos itens do instrumento foi mantida de acordo com a proposta originalmente desenvolvida por Hirata e Pilati em 2010] 


\section{References}

1. Cash TF, Smolak L (2011) Body image: a handbook of science, practice, and prevention. The guilford press, New York/London

2. Grogan S (2017) Body image: understanding body dissatisfaction in men, women and children, vol 3. Routledge, London

3. Amaral ACS, Ferreira MEC (2017) Body dissatisfaction and associated factors among Brazilian adolescents: a longitudinal study. Body Image 22(3):32-38. https://doi.org/10.1016/j.bodyi m.2017.04.006

4. Austin SB, Haines J, Veugelers PJ (2009) Body satisfaction and body weight: gender differences and sociodemographic determinants. BMC Public Health 9(1):1-7. https://doi. org/10.1186/1471-2458-9-313

5. Quittkat HL, Hartmann AS, Dusing R, Buhlmann U, Vocks S (2019) Body dissatisfaction, importance of appearance, and body appreciation in men and women over the lifespan. Front Psychiatry 10(1):1-12. https://doi.org/10.3389/fpsyt.2019.00864

6. Heider N, Spruyt A, De Houwer J (2018) Body dissatisfaction revisited: on the importance of implicit beliefs about actual and ideal body image. Psychol Belg 57(4):158-173. https://doi. org/10.5334/pb.362

7. Allen MS, Robson DA (2020) Personality and body dissatisfaction: an updated systematic review with meta-analysis. Body Image 33(1):77-89. https://doi.org/10.1016/j.bodyim.2020.02.001

8. Austin JL, Serier KN, Sarafin RE, Smith JE (2017) Body dissatisfaction predicts poor behavioral weight loss treatment adherence in overweight Mexican American women. Body image 23(4):155161. https://doi.org/10.1016/j.bodyim.2017.08.002

9. Santos Silva DA, Nahas MV, de Sousa TF, Del Duca GF, Peres KG (2011) Prevalence and associated factors with body image dissatisfaction among adults in southern Brazil: a population-based study. Body Image 8(4):427-431. https://doi.org/10.1016/j.bodyi m.2011.05.009

10. Griffiths S, Hay P, Mitchison D, Mond JM, McLean SA, Rodgers B, Massey R, Paxton SJ (2016) Sex differences in the relationships between body dissatisfaction, quality of life and psychological distress. Aust N Z J Public Health 40(6):518-522. https://doi. org/10.1111/1753-6405.12538

11. Barnes M, Abhyankar P, Dimova E, Best C (2020) Associations between body dissatisfaction and self-reported anxiety and depression in otherwise healthy men: a systematic review and metaanalysis. PLoS ONE 15(2):e0229268. https://doi.org/10.1371/ journal.pone. 0229268

12. McFarland MB, Petrie TA (2012) Male body satisfaction: factorial and construct validity of the Body Parts Satisfaction Scale for Men. J Counsel Psychol 59(2):329-337. https://doi.org/10.1037/ a0026777

13. Kling J, Kwakkenbos L, Diedrichs PC, Rumsey N, Frisen A, Brandao MP, Silva AG, Dooley B, Rodgers RF, Fitzgerald A (2019) Systematic review of body image measures. Body Image 30(3):170-211. https://doi.org/10.1016/j.bodyim.2019.06.006

14. Slade PD, Dewey ME, Newton T, Brodie D, Kiemle G (1990) Development and preliminary validation of the body satisfaction scale (BSS). Psychol Health 4(3):213-220. https://doi. org/10.1080/08870449008400391

15. Cash TF, Fleming EC, Alindogan J, Steadman L, Whitehead A (2002) Beyond body image as a trait: the development and validation of the Body Image States Scale. Eat Disord 10(2):103-113. https://doi.org/10.1080/10640260290081678

16. Hirata E, Pilati R (2010) Development and preliminary validation of the Body Satisfaction Situational Scale-ESSC [Desenvolvimento e validação preliminar da Escala Situacional de
Satisfação Corporal-ESSC]. Psico-USF 15(1):1-11. https://doi. org/10.1590/S1413-82712010000100002

17. Laus MF, Costa TM, Almeida SS (2015) Gender differences in body image and preferences for an ideal silhouette among Brazilian undergraduates. Eat Behav 19(4):159-162. https://doi. org/10.1016/j.eatbeh.2015.09.003

18. Marôco J (2014) Análise de Equações Estruturais [Structural equation analysis], 2nd edn. ReportNumber, Pêro Pinheiro

19. Swami V, Barron D (2019) Translation and validation of body image instruments: challenges, good practice guidelines, and reporting recommendations for test adaptation. Body Image 31(1):204-220. https://doi.org/10.1016/j.bodyim.2018.08.014

20. Brown TA (2015) Confirmatory factor analysis for applied research, vol 2. Guilford Press, New York

21. Muthén LK, Muthén BO (2017) MPlus: statistical analysis with latent variables user's guide. www.StatModel.com. Accessed 19 Oct 2020

22. WHO (2000) Obesity: preventing and managing the global epidemic. Technical Report Series. World Health Organization, Geneva

23. ABEP (2019) Brazilian economic classification criteria. Brazilian Association of Research Companies. http://www.abep.org/crite rio-brasil. Accessed May 2020

24. Hair JF Jr, Black WC, Babin B, Anderson RE (2009) Multivariate data analysis, 7th edn. Prentice Hall, Upper Saddle River

25. Hu L, Bentler PM (1999) Cutoff criteria for fit indexes in covariance structure analysis: conventional criteria versus new alternatives. Struct Equ Model 6(1):1-55. https://doi.org/10.1080/10705 519909540118

26. Byrne BM (2001) Structural equation modeling with Amos: basic concepts, applications and programming. Lawrence Erlbaum Associates, New Jersey

27. Fornell C, Larcker DF (1981) Evaluating structural equation models with unobservable variables and measurement error. J Mark Res 18(1):39-50. https://doi.org/10.2307/3151312?uid=37376 $64 \&$ uid $=2 \&$ uid $=4 \&$ sid $=21103223270061$

28. Dunn TJ, Baguley T, Brunsden V (2014) From alpha to omega: a practical solution to the pervasive problem of internal consistency estimation. Br J Psychol 105(3):399-412. https://doi.org/10.1111/ bjop. 12046

29. Cheung GW, Rensvold RB (2002) Evaluating goodness-of-fit indexes for testing measurement invariance. Struct Equ Model 9(2):233-255. https://doi.org/10.1207/S15328007SEM0902_5

30. Petrie TA, Tripp MM, Harvey P (2002) Factorial and construct validity of the Body Parts Satisfaction Scale—revised: an examination of minority and nonminority women. Psychol Women Q 26(3):213-221. https://doi.org/10.1111/1471-6402.00060

31. Jankowski GS, Gough B, Fawkner H, Halliwell E, Diedrichs PC (2018) Young men's minimisation of their body dissatisfaction. Psychol Health 33(11):1343-1363. https://doi.org/10.1080/08870 446.2018.1496251

32. Mustapic J, Marcinko D, Vargek P (2017) Body shame and disordered eating in adolescents. Curr Psychol 36(3):447-452. https ://doi.org/10.1007/s12144-016-9433-3

33. Sun Q (2018) Materialism, body surveillance, body shame, and body dissatisfaction: testing a mediational model. Front Psychol 9(1):1-4. https://doi.org/10.3389/fpsyg.2018.02088

34. Sarwer DB (2019) Body image, cosmetic surgery, and minimally invasive treatments. Body Image 31(4):302-308. https://doi. org/10.1016/j.bodyim.2019.01.009

Publisher's Note Springer Nature remains neutral with regard to jurisdictional claims in published maps and institutional affiliations. 